\title{
Anopheles (Anopheles) petragnani Del Vecchio 1939-a new mosquito species for Germany
}

\author{
Norbert Becker $^{1,2}$ (D) Wolf Peter Pfitzner ${ }^{1}$ - Christina Czajka ${ }^{1}$ - Achim Kaiser ${ }^{1}$. \\ Thomas Weitzel ${ }^{1}$
}

Received: 7 March 2016 / Accepted: 10 March 2016/Published online: 22 March 2016

(C) The Author(s) 2016. This article is published with open access at Springerlink.com

\begin{abstract}
The so far known species of the Anopheles Claviger Complex, Anopheles claviger s.s. and Anopheles petragnani, can only be distinguished by partial overlapping characteristics of immature stages and by nucleotide sequence variation of the genomic ribosomal DNA (rDNA) internal transcribed spacer 2 (ITS2) region. The known distribution of An. petragnani is so far restricted to the western Mediterranean region, whereas An. claviger s.s. occurs across most of Europe, up to the Middle East and North Africa. In our study, we investigated the larval mosquito fauna in rock pools of the Murg valley (Black Forest, Germany) once a month from April to December 2015.

Among other species, larvae belonging to the Anopheles Claviger Complex were found. The fourth instar larvae were morphologically identified by chaetotaxy of the head and abdomen. The results were confirmed by a multiplex PCR and additional sequencing of the amplificates.
\end{abstract}

Norbert Becker

norbertfbecker@web.de

Wolf Peter Pfitzner

wolf-peter.pfitzner@kabs-gfs.de

Christina Czajka

christina.czajka@kabs-gfs.de

Achim Kaiser

achim.kaiser@kabs-gfs.de

Thomas Weitzel

Thomas.weitzel@kabs-gfs.de

1 German Mosquito Control Association (KABS), Institute for Dipterology, Georg-Peter-Süß-Str. 3, 67346 Speyer, Germany

2 Ruprecht-Karls-Universität Heidelberg, Im Neuenheimer Feld 230, 69120 Heidelberg, Germany
Of the 1289 collected larvae from the rock pools, seven belonged to the Anopheles Claviger Complex. Five individuals were determined morphologically as An. petragnani and two as An. claviger s.s. The associated mosquito fauna comprised of Aedes japonicus japonicus (548 individuals), Culex pipiens s.l. and Culex torrentium (493 individuals) and Culex hortensis (241 individuals).

This is the first record of An. petragnani north of the Alps. Further studies will reveal whether this is an isolated population of An. petragnani and if the investigated rock pool breeding sites represent typical habitats of this species in temperate regions in Central Europe.

Keywords Anopheles petragnani $\cdot$ Anopheles Claviger Complex $\cdot$ Rock pools $\cdot$ Chaetotaxy $\cdot$ ITS2

\section{Introduction}

Anopheles (Anopheles) claviger s.s. (Meigen, 1804) and Anopheles (Anopheles) petragnani Del Vecchio, 1939 are sibling species, forming the Anopheles Claviger Complex, as males and females cannot be distinguished by morphological characteristics. However, both species differ considerably in their egg, larval and pupal morphology, as well as in their adult behaviour. An. petragnani was first described by Del Vecchio in 1939 as a variety of An. claviger, distinguished by the shape of the eggs (Del Vecchio 1939). Coluzzi highlighted the larval and pupal differences between these forms and proved, using cross-mating studies, that they are two distinct species (Coluzzi 1960; Coluzzi 1962). Since then, An. petragnani has only been found in the western Mediterranean area, mainly in coastal regions (Ramsdale and Snow 2000). The larvae usually develop along river beds 
in fresh water rock pools or in ditches and drainage canals (Marchi and Munstermann 1987).

An. claviger s.s. is a Palaearctic species that is distributed all over Europe, the Middle East and North Africa (Ramsdale and Snow 2000). The larvae are found in a wide variety of breeding sites, but in general occur in unpolluted, semipermanent and permanent water bodies (Becker et al. 2010). They are more adapted to colder water temperatures than $A n$. petragnani, which results in a wider distribution area towards the North. In warmer, Mediterranean regions, An. claviger s.s. exploits colder breeding sites such as wells and underground water bodies (Coluzzi 1962; Ramsdale and Snow 2000). In the geographic range of An. petragnani, both species are sympatric and can also be associated in the same breeding sites (Coluzzi 1960). In the Upper Rhine Valley in southwest Germany, An. claviger s.s. is a common mosquito species and can be found regularly (Becker and Kaiser 1995).

Little is known about rock pool mosquito species diversity in Germany. Only Vogel (Vogel 1933) has reported on the occurrence of Culex (Maillotia) hortensis Ficalbi, 1889 and Culiseta (Culiseta) glaphyroptera (Schiner, 1864) in rock pools in the Murg valley, Black Forest. Therefore, in 2015, a monitoring programme was initiated to survey the occurrence of rock pool mosquitoes in this region, primarily with a special emphasis on Aedes (Hulecoeteomyia) japonicus japonicus (Theobald, 1901). This survey led to the recording of An. petragnani larvae in the investigated rock pools of the river Murg in August 2015.

After this first detection of An. petragnani, a study on the larval morphology of both sibling species belonging to the Anopheles Claviger Complex was initiated. The species differentiation in larval seta distribution (Coluzzi 1960; Coluzzi et al. 1965) was analysed and verified using a specific PCR assay (Kampen et al. 2003; Sternberg 2004) in combination with sequencing of the nuclear ribosomal internal transcribed spacer 2 (ITS2) region.

\section{Method}

\section{Mosquito origin}

Twelve rock pools in the Murg valley at Raumünzach (Black Forest, $48.633 \mathrm{~N}, 8.356 \mathrm{E}, 420$ m a.s.l.; Germany, Fig. 1) were monitored once a month from April to December 2015. In

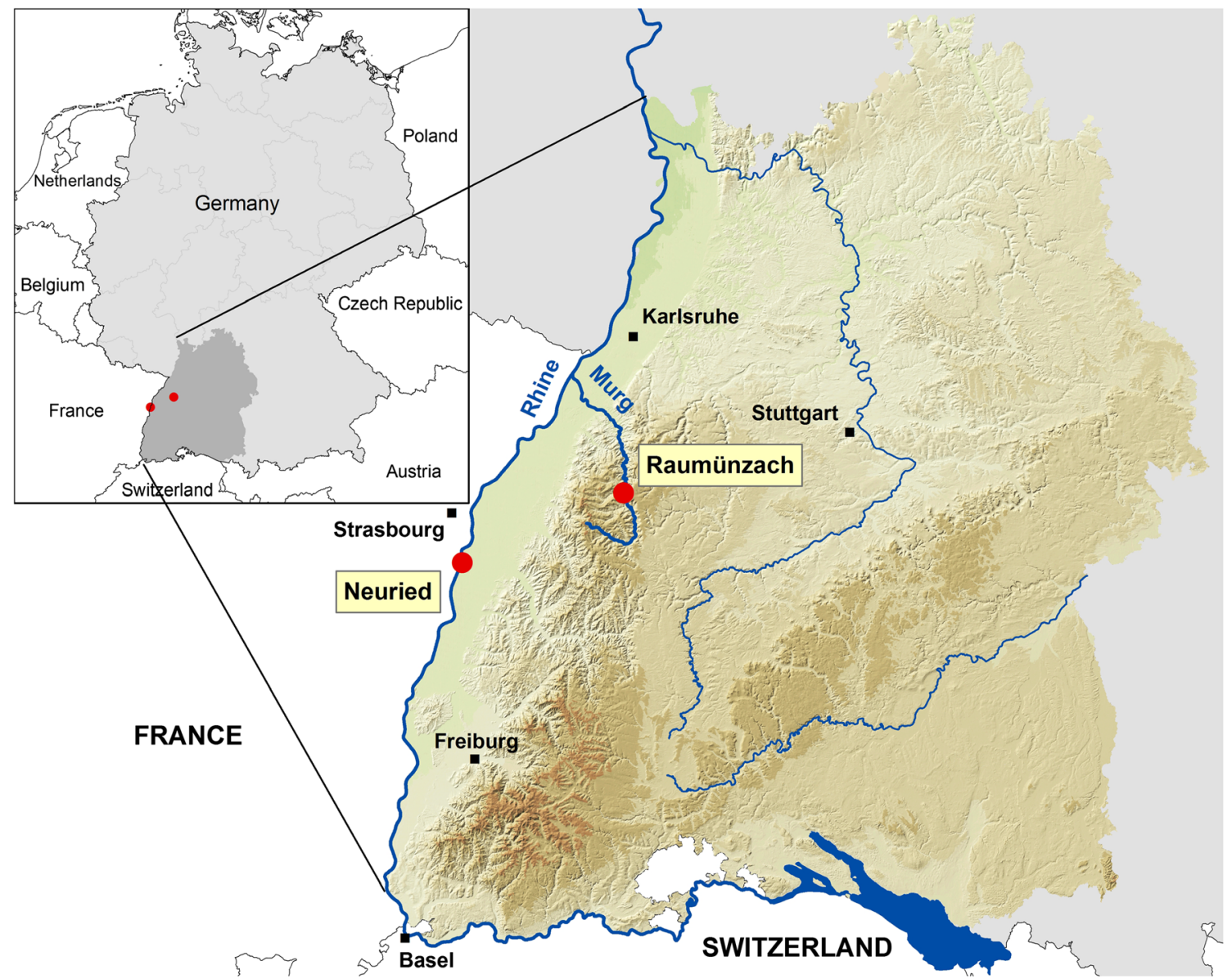

Fig. 1 Map of Baden-Wuerttemberg, Germany. The red dots indicate the trapping sites at the river Murg in the Black Forest (Raumünzach) and in the flood plains of the river Rhine (Neuried) 
each breeding site and at each sampling, 10 dips with a WHO standard dipper $(350 \mathrm{ml})$ were taken and sieved through a net. The larvae were reared to the fourth instar in the lab and transferred into vessels with $70 \%$ ethanol for species determination and assessment of the species composition.

For morphological comparison, additional larvae belonging to the Anopheles Claviger Complex were collected in September 2015 in ditches with little vegetation in the floodplains of the river Rhine near the municipality of Neuried (48.459 N, 7.772 E; $145 \mathrm{~m}$ a.s.1.) (Fig. 1).

\section{Abiotic parameters of the breeding sites}

The abiotic parameters, $\mathrm{pH}$ value, conductivity, water temperature, carbonate hardness, total hardness, ammonium, nitrite and nitrate, as well as phosphate, were determined at each sampling date by employing the following test sets: $\mathrm{pH}$ using a pocket $\mathrm{pH}$ metre (Amarell Electronic), conductivity and temperature (Hanna instruments, Australia, HI98129) and all other parameters with the Compact Laboratory for Water Testing (Merck 1.11151.0001).

\section{Morphological identification}

The fourth instar larvae were morphologically identified according to the key of Becker et al. (2010). To improve determination, some larvae were mounted in Euparal. The diagnostic characters used to distinguish An. claviger s.s. from $A n$. petragnani were the number of branches of the postclypeal setae (4-C), as well as the number of branches of the antepalmate setae of the abdominal segments IV and V (2IV and 2-V). According to Becker et al. (2010), the postclypeal setae of the fourth instar larvae of An. claviger s.s. possess two to five branches and the antepalmate setae three to five branches. In An. petragnani, the postclypeal setae are usually single, but sometimes with two branches, and the antepalmate setae have one to three branches.

\section{Molecular identification}

After morphological classification, the anopheline larvae were determined using a PCR of the second internal transcribed spacer (ITS2) region of mosquito ribosomal DNA (rDNA). Therefore, DNA from all the collected specimens was extracted with QuickExtract ${ }^{\mathrm{TM}}$ DNA Extraction Solution 1.0 (epicentre, Madison, WI, USA), following the manufacturer's manual, and kept frozen at $-20{ }^{\circ} \mathrm{C}$ until further use.

PCR analysis was performed with the universal f-primer 5.8S (5'-TGTGAACTGCAGGACACATG-3') and two species-specific r-primers: 5'-GCAACACT TTGGTGGCCAC-3' (An. petragnani) and 5'-CTAGCAAG TGCACTGTGTCC-3' (An. claviger s.s.) (Kampen et al. 2003; Sternberg 2004). The amplificates of 367 bp (An. petragnani) and $269 \mathrm{bp}$ (An. claviger s.s.), respectively, within the ITS2 sequence reliably distinguish both species.

The PCR mixture was made up of $10 \mu \mathrm{l} 5 \times$ Phire Green Reaction Buffer (containing $1.5 \mathrm{mM} \mathrm{MgCl}_{2}$ at the final $1 \times$ reaction concentration), $1 \mu$ l Phire Hot Start II DNAPolymerase $\left(20 \mathrm{mM}\right.$ Tris- $\mathrm{HCl}\left(\mathrm{pH} 7.4\right.$ at $\left.25^{\circ} \mathrm{C}\right), 0.1 \mathrm{mM}$ EDTA, $1 \mathrm{mM}$ DTT, $100 \mathrm{mM} \mathrm{KCl}$, stabilisers, $200 \mu \mathrm{g} / \mathrm{ml}$ BSA, $50 \%$ glycerol) (both Thermo Scientific, Waltham, MA, USA), $1 \mu \mathrm{l}$ dNTPs (200 $\mu \mathrm{M}$ each), $1 \mu \mathrm{l}$ of each primer (200 nM), and $2 \mu \mathrm{l}$ DNA solution and water, adding up to a total reaction volume of $50 \mu \mathrm{l}$. For the negative control, $2 \mu \mathrm{l}$ of water was used instead of DNA.

The cycling protocol began with an initial denaturation step of $30 \mathrm{~s}$ at $98^{\circ} \mathrm{C}$, followed by 30 cycles, consisting of denaturation at $98^{\circ} \mathrm{C}$ for $5 \mathrm{~s}$, annealing at $52^{\circ} \mathrm{C}$ for $45 \mathrm{~s}$, as well as elongation for $15 \mathrm{~s}$ at $72{ }^{\circ} \mathrm{C}$, and ended with a final elongation step at $72{ }^{\circ} \mathrm{C}$ for $60 \mathrm{~s}$.

From each PCR-product, $5 \mu \mathrm{l}$ was loaded on a $1.2 \%$ agarose gel in a FlashGel ${ }^{\mathrm{TM}}$ System (Rockland, ME, USA). Electrophoresis was run for $10 \mathrm{~min}$ at $200 \mathrm{~V}$ to verify the species-specific size of the amplicons.

All amplificates of An. petragnani and a representative number of amplificates of An. claviger s.s. were further prepared for sequencing, using the GF-1 PCR Clean-up Kit, according to the manufacturer's instructions (Vivantis, Oceanside, CA, USA). The sequencing reactions were carried out by Eurofins Genomics (Ebersberg, Germany).

\section{Results}

\section{Species composition}

In two of the 12 analysed Murg rock pools, seven anopheline larvae were sampled in August and September 2015. Four of them were identified by morphological and molecular methods as An. petragnani and two of them as An. claviger s.s. A single male, hatched from the pupal stage, was also determined as An. petragnani, however only by PCR.

In the floodplains of Neuried, only An. claviger s.s. was found. All 20 larvae were determined morphologically, whereas 15 were additionally confirmed by PCR.

The total mosquito fauna in the rock pools was assayed by 1050 dips and included 1289 mosquito larvae. The exotic species Ae. j. japonicus was represented by 548 larvae (42.5\%). Four hundred ninety three larvae (38.2\%) were determined as Culex (Culex) pipiens L. 1758 and Culex (Culex) torrentium Martini, 1925, respectively, and 241 larvae (18.7\%) as C. hortensis. The proportion of Anopheles Claviger Complex larvae was $0.5 \%$.

Associated faunal taxa in the rock pools were Cladocera, Asellus aquaticus, Velia sp., Hydrometra gracilis, Laccobius striatulus (Dytiscidae), Dryopidae, Chironomidae (e.g. 
Tanypus sp.), Tipulidae, Trichoptera, Ephemeridae, Plecoptera and Bombina variegata.

Three plant species were found: Hygroamblystegium fluviatile, Brachythecium rivulare and filamentous algae (Spirogyra sp.).

\section{Abiotic parameters of the breeding sites}

The rock pool breeding sites were characterised by an alkaline $\mathrm{pH}$, low conductivity and low values of hardness. The values for ammonium, nitrite, nitrate and phosphate were either below the limits of detection or very low (Table 1).

\section{Diagnostic morphological characters of $A n$. petragnani and $A$ n. claviger s.s. larvae}

The number of branches of the postclypeal setae (4-C) of the larvae of An. petragnani ranged from one to two, but was usually one. When two branches were counted, the second was much smaller than the main one. The number of antepalmate seta branches (2VI and $2 \mathrm{~V}$ ) ranged from two to three, but in general was two (Table 2, Fig. 2).

In An. claviger s.s., the number of branches in the postclypeal setae was usually two to three, but ranged from one to four. The number of antepalmate seta branches ranged from three to six, but three to five were usually counted.

\section{Determination of An. claviger s.l. by PCR-based diagnostics}

Individuals belonging to the Anopheles Claviger Complex (altogether 22 samples) were further investigated using a species-specific PCR (Kampen et al. 2003; Sternberg 2004) to verify the morphological classification. Five samples showed positive signals for An. petragnani, the remaining 17 for An. claviger s.s. Figure 3 illustrates the speciesspecific PCR fragments after agarose gel electrophoresis of 10 samples, of which five were An. petragnani (from the

Table 1 Abiotic parameters of the rock pools in the Murg and the floodplains of the river Rhine

\begin{tabular}{lll}
\hline Sampling site & Murg (rock pools) & Rhine floodplains \\
\hline $\mathrm{pH}$ & 8.35 & 7.02 \\
Conductivity $[\mu \mathrm{S}]$ & 30 & 690 \\
Total hardness $\left[\mathrm{dH}^{\circ}\right]$ & 2.4 & 19.7 \\
Carbonate hardness $\left[\mathrm{dH}^{\circ}\right]$ & 2.5 & 11.6 \\
Ammonium $[\mathrm{mg} / \mathrm{l}]$ & $<0.2$ & $<1$ \\
Nitrite $[\mathrm{mg} / \mathrm{l}]$ & 0 & 25 \\
Nitrate $[\mathrm{mg} / \mathrm{l}]$ & 0 & $<10$ \\
Phosphate $[\mathrm{mg} / \mathrm{l}]$ & 0 & $<0.5$ \\
\hline
\end{tabular}

Table 2 Number of branches of postclypeal and antepalmate setae for the three populations of An. claviger s.1

\begin{tabular}{lllllll}
\hline Postclypeal setae (4-C) no. of branches & 1 & 2 & 3 & 4 & 5 & 6 \\
An. claviger s.s. (R) & 4 & 13 & 20 & 2 & & \\
An. claviger s.s. (M) & & 1 & 3 & & & \\
An. petragnani (M) & 6 & 2 & & & & \\
Antepalmate setae (2-IV + 2-V) no. of branches & 1 & 2 & 3 & 4 & 5 & 6 \\
An. claviger s.s. (R) & & & 21 & 36 & 22 & 1 \\
An. claviger s.s. (M) & & & 1 & 2 & 3 & 2 \\
An. petragnani (M) & 13 & 2 & & & \\
\hline
\end{tabular}

Provided are the numbers of counted setae with the corresponding numbers of branches per seta. An. claviger s.s. Neuried: 20 individuals; $A n$. claviger s.s. Murg: 2 individuals; An. petragnani Murg: 4 individuals. Setae not counted were absent $(R$ Rhine, $M$ Murg)

Black Forest, 367 bp) and five An. claviger s.s. (269 bp, samples 6 and 7 originating from the Black Forest, samples $8-10$ from the Rhine floodplain).

The sequencing of all amplificates confirmed the results of both the morphological classification as well as the PCR by blasting the obtained sequences in NCBI and comparing them to the already inscribed sequences of An. petragnani (accession number GenBank AY129233.1) and An. claviger s.s. (accession number GenBank AY129232.1).

The alignment of all the sequences is shown in Fig. 4. The Murg An. petragnani ITS2 sequence revealed three SNPs and two indels compared to the consensus sequence from the Mediterranean samples published in GenBank.

\section{Discussion}

This is the first time that An. petragnani has been recorded north of the Alps. So far, this species was only found in the western Mediterranean area in Italy, including Sardinia (Coluzzi et al. 1965; Marchi and Munstermann 1987; Romi et al. 1997), France including Corsica (Coluzzi et al. 1965; Schaffner 1998), Spain (Encinas Grandes 1982; Eritja et al. 1998), Portugal (Pires et al. 1982; Ramos et al. 1977; Ribeiro et al. 1988; Ribeiro et al. 1996) and North Africa (Coluzzi et al. 1965; Senevet and Andarelli 1955). Coluzzi (1962) found An. petragnani to be a more thermophilic species than An. claviger s.s. Therefore, it is surprising to find An. petragnani outside of its previously known range in the Mediterranean climate. Based on published distribution data, it appears to be an isolated population in the mountains of the Black Forest. Despite intense research, it could not yet be found in the neighbouring Vosges and most parts of France, except for the known southern regions (Kampen et al. 2003; Schaffner et al. 2003).

In contrast to An. petragnani, An. claviger s.s. is distributed all over Europe, extending east towards Afghanistan and south into North Africa (Ramsdale and Snow 2000). An. 
Fig. 2 Diagnostic setae of $A n$. claviger s.l. larvae. a Postclypeal setae of An. petragnani. b Postclypeal setae of An. claviger s.s. c Antepalmate setae of abdominal segments IV and V of An. petragnani. d Antepalmate setae of abdominal segments IV and $\mathrm{V}$ of An. claviger s.s.

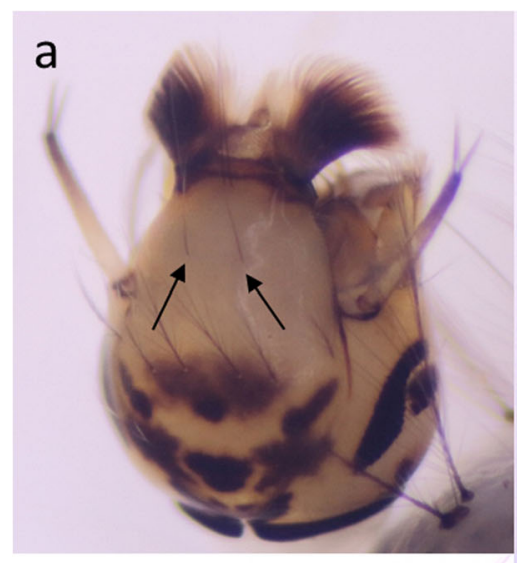

b

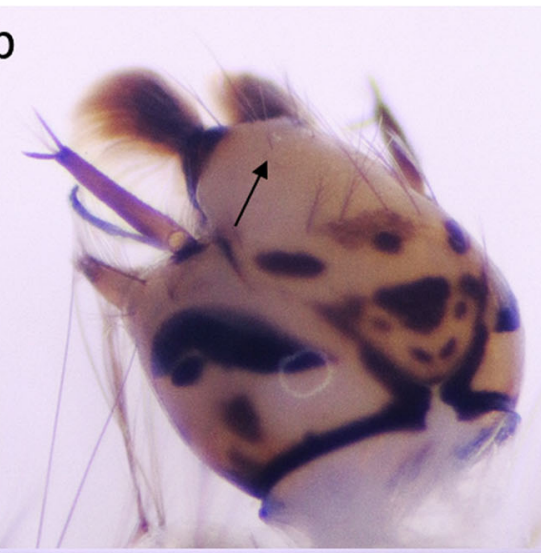

C

d

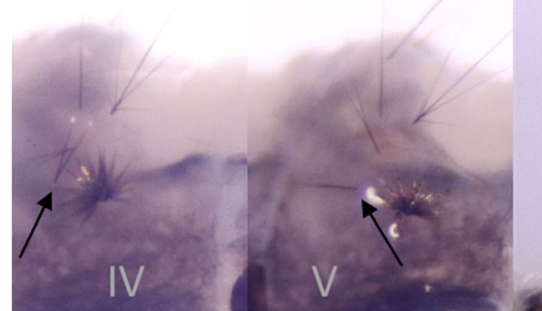

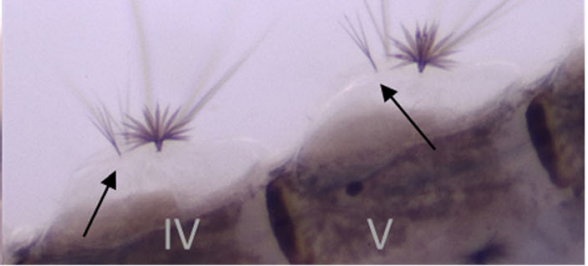

claviger s.s. is more widely distributed in northern Europe and exploits cold water issuing from springs, wells and underground cisterns in Mediterranean regions (Coluzzi 1962).

For differentiating the sibling species, we used the chaetotaxy described by Coluzzi (1960) as well as a speciesspecific PCR-based diagnostic assay (Kampen et al. 2003; Sternberg 2004). The combination of morphological and molecular-based determination techniques allowed us to

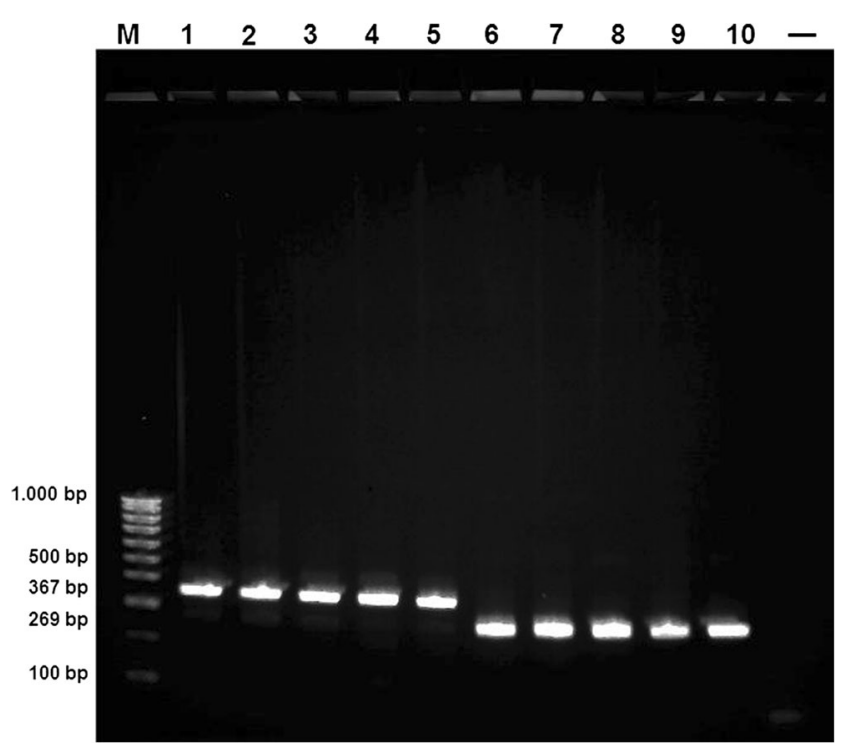

Fig. 3 Species diagnostic internal transcribed spacer 2 (ITS2) fragments from all An. petragnani (367 bp) and some An. claviger s.s. (269 bp) individuals found during this study $(M$, Quantitas DNA Marker $100 \mathrm{bp}-1 \mathrm{~kb}$, Biozym; lanes 1-5, An. petragnani; lanes 6-10, An. claviger s.s.; - negative control) distinguish reliably between the two species and enabled us to review the variability and slight overlap in the number of diagnostic setae of larval stages. Reliable species discrimination is essential for the analysis of the bionomics of An. claviger s.s. and $A n$. petragnani, such as preferred breeding sites, specific biting behaviour and vector competence, particularly for malaria parasites. According to the literature, it seems that $A n$. claviger s.s. has a much broader ecological range than $A n$. petragnani. So far, the latter was found in freshwater rock pools, ditches, drainage canals, edges of rivers and streams (Marchi and Munstermann 1987), but also in artificial breeding sites like wells and cisterns (Romi et al. 1997).

Exotic species, such as Ae.j. japonicus or Aedes (Stegomyia) albopictus (Skuse, 1895), are usually introduced by the transportation of desiccation-resistant eggs (Becker et al. 2011; Pluskota et al. 2008). This is unlikely for anopheline species, which usually lay their eggs directly on the water surface. How the breeding sites in the Black Forest were colonised by An. petragnani so far away from its known distribution area is of particular zoogeographic interest. A recent introduction of An. petragnani to the Murg valley seems unlikely, as the ITS2 sequence differentiation between the Mediterranean An. petragnani and the Murg population is considerable, consisting of three SNPs and two indels. This differentiation indicates a discontinuous geographical distribution without gene flow due to isolation by distance. Based on this assumption, the Murg population might be the relict of a warmer postglacial period in the early Holocene, when the distribution of An. petragnani probably extended further north and maybe was not fragmented. 


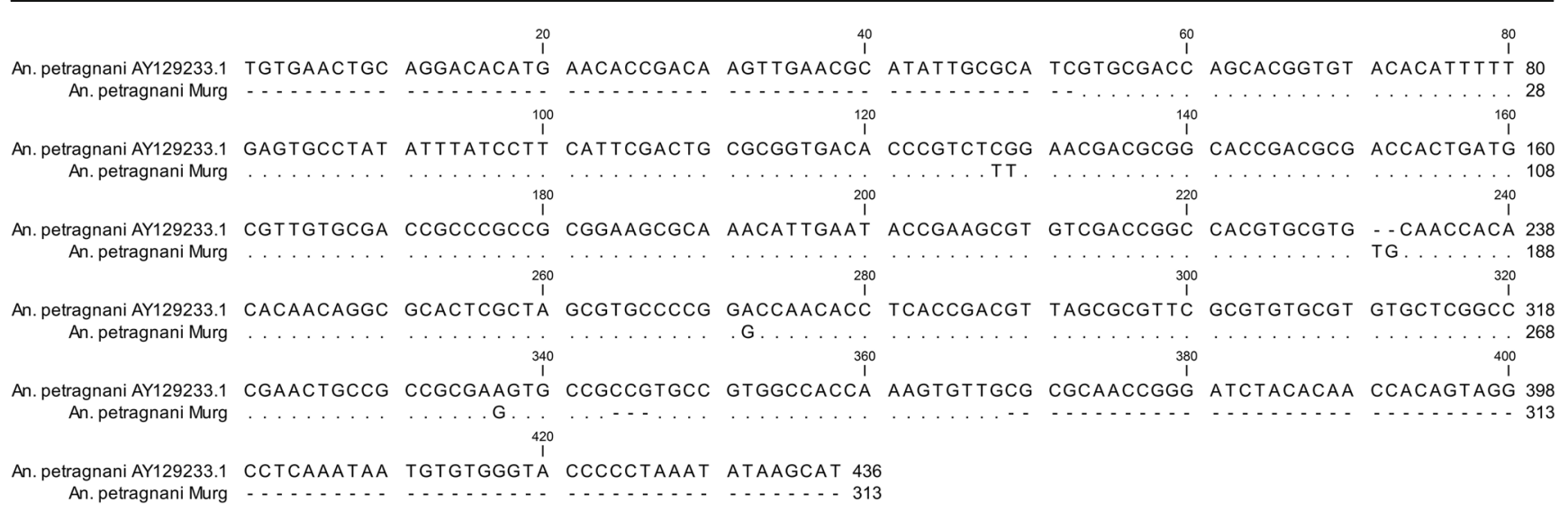

Fig. 4 Alignment of the An. petragnani consensus sequence obtained during this study with the An. petragnani consensus sequence published under AY129233.1 in GenBank

Also minor differences in the number of branches in the antepalmate setae of the Murg and Mediterranean An. petragnani populations could be found. However, this observation is based only on a small sample size. In the four larvae examined in this study, two branches were usually counted, whereas Coluzzi reported three branches to be common (Coluzzi 1960).

In the Murg rock pools, little vegetation was present, and only the water mosses $H$. fluviatile and $B$. rivulare as well as filamentous algae were present. It remains unclear whether the occurrence of water mosses is important for the breeding site choice and egg deposition of the anopheline females (Pires et al. 1982). Anopheline larvae could be found in breeding sites where the water moss lined the edges of the water bodies and never in potential breeding sites consisting of pure granite (Fig. 5).

This finding of An. petragnani is the seventh record of a so far unknown or newly introduced mosquito species in Germany since the middle of the 1990s, alongside

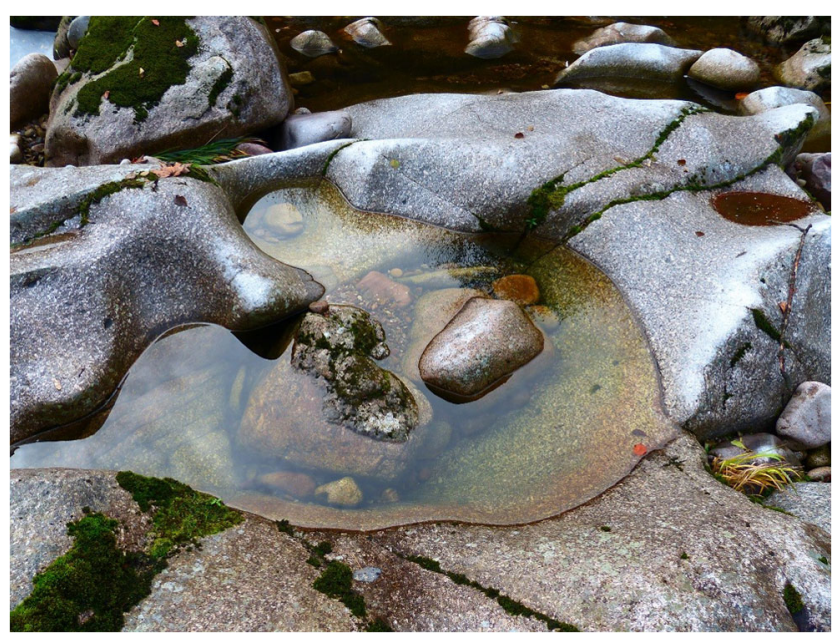

Fig. 5 Rock pool in the granite river bed of the Murg
Uranotaenia (Pseudoficalbia) unguiculata Edwards, 1913 (Becker and Kaiser 1995), Ae. albopictus (Becker et al. 2013; Pluskota et al. 2008), Ae. j. japonicus (Becker et al. 2011; Schaffner et al. 2009), Culiseta (Allotheobaldia) longiareolata (Macquart, 1838) (Becker and Hoffmann 2011), Anopheles (Anopheles) daciae Linton, Nicolescu \& Harbach 2004 (Weitzel et al. 2012) and Aedes (Finlaya) koreicus (Edwards, 1917) (Werner et al. 2015).

Further research is required to define the occurrence of both sibling species of the Anopheles Claviger Complex, with a focus on niche breeding sites in temperate regions, like rock pools, that could be favourable for An. petragnani. This would also answer the question whether An. petragnani in the Black Forest is an isolated population. Sequencing of the complete ITS2 region and analysis of potential geographic variation in nucleotide sequences could provide further information on the origin of the German An. petragnani population and the dispersal of both An. petragnani and An. claviger s.s. as a result of climate variation and space-time processes.

Acknowledgments We greatly appreciate the support of MSc. Christina Manz for the extraction of the DNA, as well as Salvatore, Benjamin and Daniela Lanzalaco for their translation of the Italian publications. We appreciate the help of Dipl.-Biol. Matthias Beck for determining the moss species.

Authors' contributions NB collected field data, designed the work and contributed substantially to the manuscript. WPP performed the chaetotaxy as well as the evaluation of the morphological characters and made substantial contribution to the interpretation of the data and to the manuscript. CC carried out the PCR-based determination and contributed substantially in preparing the molecular part of the manuscript. AK coordinated the work on chaetotaxy and contributed substantially to the manuscript. TW coordinated the molecular-based activities and revised critically the content of the manuscript. All authors read and approved the final manuscript.

\section{Compliance with ethical standards}

Competing interests The authors declare that they have no competing interests. 
Open Access This article is distributed under the terms of the Creative Commons Attribution 4.0 International License (http:// creativecommons.org/licenses/by/4.0/), which permits unrestricted use, distribution, and reproduction in any medium, provided you give appropriate credit to the original author(s) and the source, provide a link to the Creative Commons license, and indicate if changes were made.

\section{References}

Becker N et al (2013) Repeated introduction of Aedes albopictus into Germany, July to October 2012. Parasitol Res 112(4):1787-90. doi:10.1007/s00436-012-3230-1

Becker N, Hoffmann D (2011) First record of Culiseta longiareolata (Macquart) for Germany. European Mosq Bulletin 29:143-150

Becker N, Huber K, Pluskota B, Kaiser A (2011) Ochlerotatus japonicus japonicus - a newly established neozoan in Germany and a revised list of the German mosquito fauna. European Mosq Bulletin 29:88-102

Becker N, Kaiser A (1995) Die Culicidenvorkommen in den Rheinauen des Oberrheingebiets mit besonderer Berücksichtigung von Uranotaenia (Culicidae, Diptera) - einer neuen Stechmückengattung für Deutschland. Mitt dtsch Ges allg angew Ent 10:407-413

Becker N et al (2010) Mosquitoes and their control, 2nd edn. Springer, Heidelberg, Dordrecht, London, New York

Coluzzi M (1960) Alcuni dati morfologici e biologici sulle forme italiane di Anopheles claviger Meigen. Riv Malariologia 39:1-17

Coluzzi M (1962) Le forme di Anopheles claviger Meigen indicate con i nomi missirolii e petragnanii sono due specie riprodutticamente isolate. Rend Accad Naz Lincei 32(6):1025-1030

Coluzzi M, Saccà G, Feliciangeli D (1965) Il complesso Anopheles claviger nella sottoregione Mediterranea. Cah ORSTOM, Ser Ent Parasit 3:97-102

Del Vecchio G (1939) Sulle varietà di A. claviger (Bifurcatus). Riv Parassitol 3(1):27-37

Encinas Grandes A (1982) Taxonomía y biología de los mosquitos del área salmantina (Díptera, Culicidae). Consejo Superior de Investigaciones Científicas. Centro de Edafología y Biología aplicada, Ediciones Universidad de Salamanca, Salamanca

Eritja R, Aranda C, Padrós J, Goula M (1998) Revised checklist of the Spanish mosquitoes. Acta Parasitol 5(25)

Kampen $\mathrm{H}$ et al (2003) Polymerase chain reaction-based differentiation of the mosquito sibling species Anopheles claviger s.s. and Anopheles petragnani (Diptera: Culicidae). Am J Trop Med Hyg 69(2):195-9
Marchi A, Munstermann LE (1987) The mosquitoes of Sardinia: species records 35 years after the malaria eradication campaign. Med Vet Entomol 1(1):89-96

Pires AC, Ribeiro H, Capela RA, da Cunha RH (1982) Research on the mosquitoes of Portugal (Diptera, Culicidae) VI-the mosquitoes of Alentejo. An do Inst de hig e med trop 8:79-102

Pluskota B, Storch V, Braunbeck T, Beck M, Becker N (2008) First record of Stegomyia albopicta (Skuse) (Diptera: Culicidae) in Germany. European Mosq Bulletin 26:1-5

Ramos HC, Ribeiro H, Pires CA, Capela RA (1977) Research on the mosquitoes of Portugal (Diptera, Culicidae) II- the mosquitoes of Algarve. An Instit Hig Med Trop 5(1-4):236-56

Ramsdale C, Snow K (2000) Distribution of the genus Anopheles in Europe. European Mosq Bull 7:1-26

Ribeiro H, Da Cunha Ramos H, Pires CA, Antunes Capela R (1988) An annotated checklist of the mosquitoes of continental Portugal (Diptera Culicidae). Congreso Ibérico de Entomologia Actas III:233-254

Ribeiro H, Pires CA, Ramos HC (1996) Os mosquitos do Parque Natural da Arrábida. Garcia de Orta: série de zoologia 21(1):81-110

Romi R, Pontuale G, Sabatinelli G (1997) Le zanzare italiaine: generalita e identificazione degli stadi preimaginali (Diptera, Culicidae). Fragm Entomol 29:141

Schaffner F (1998) A revised checklist of the French Culicidae. European Mosq Bull 2:1-9

Schaffner F, Kaufmann C, Hegglin D, Mathis A (2009) The invasive mosquito Aedes japonicus in Central Europe. Med Vet Entomol 23(4):448-51. doi:10.1111/j.1365-2915.2009.00825.x

Schaffner F, Marquine M, Pasteur N, Raymond M (2003) Genetic differentiation of Anopheles claviger s.s. in Europe. J Med Entomol 40(6): $865-75$

Senevet G, Andarelli L (1955) Races et variétés de l'Anopheles claviger Meigen, 1804. Arch Inst Pasteur Alger 33(2):128-37

Sternberg A (2004) Molekularbiologische Differenzierung der Geschwisterarten des Anopheles claviger-Komplexes und Untersuchungen zur Populationsgenetik von Anopheles claviger s.s. Meigen 1804 (Diptera, Culicidae) auf der Basis von Mutationen in der mitochondrialen DNA. Dissertation. JustusLiebig-Universität Gießen. 123 pp

Vogel R (1933) Zur Kenntnis der Stechmücken Württembergs. I. Teil. Jh Ver vaterl Naturkd Württ 85:258-277

Weitzel T, Gauch C, Becker N (2012) Identification of Anopheles daciae in Germany through ITS2 sequencing. Parasitol Res 111:24312438. doi:10.1007/s00436-012-3102-8

Werner D, Zielke DE, Kampen H (2015) First record of Aedes koreicus (Diptera: Culicidae) in Germany. Parasitol Res. doi:10.1007/ s00436-015-4848-6 